Original Research Article

\title{
Anti-stress activity of Ocimum sanctum and alprazolam in animal models
}

\author{
G. V. Hemanth, B. L. Kudagi*, Madhavulu Buchineni, \\ Rama Mohan Pathapati, Sriharsha Rayam
}

Department of Pharmacology, Narayana Medical College, Nellore, Andhra Pradesh, India

Received: 19 June 2019

Revised: 12 September 2019

Accepted: 13 September 2019

*Correspondence to:

Dr. B. L. Kudagi,

Email: blkudagi@rediffmail. com

Copyright: (C) the author(s), publisher and licensee Medip Academy. This is an openaccess article distributed under the terms of the Creative Commons Attribution NonCommercial License, which permits unrestricted noncommercial use, distribution, and reproduction in any medium, provided the original work is properly cited.

\begin{abstract}
Background: Stress is the physiological, psychological and behavioral response by individuals when they perceive a lack of equilibrium between the demands placed upon them and their ability to meet those demands, which over a period of time leads to ill health. There are several ways of coping with stress. Some techniques of time management may help a person to control stress.

Methods: Forced swim test- mice were randomized into two groups according to the body weights. Each group contains six animals. Each individual animal was allowed to swim inside the jar $(25-12-25 \mathrm{~cm})$ containing fresh water up to $15 \mathrm{~cm}$ height. Mice were allowed swim for $6 \mathrm{~min}$. After initial struggle to escape the animal became immobile. Total immobility period was measured. Rotarod test- mice were randomized into two groups according to body weights. Each group contains six animals. Rats were placed on the lanes. Latency period was recorded at which each rat falls off the rod.
\end{abstract}

Results: In first experiment, anti-stress activity of Ocimum sanctum in mice was demonstrated by measuring the immobility period during forced swim test and in the second experiment the measurement of the latency period of rats in rotarod apparatus was performed. Both the experimental procedures were compared with standard anti stress drug alprazolam.

Conclusions: The present study suggests that Ocimum sanctum possess significant anti stress activity but less when compared to alprazolam.

Keywords: Stress, Ocimum sanctum, Alprazolam, Forced swim test, Rotarod test

\section{INTRODUCTION}

Stress is the physiological, psychological and behavioral response by individuals when they perceive a lack of equilibrium between the demands placed upon them and their ability to meet those demands, which over a period of time leads to ill health. Stress is the emotional and physical strain caused by our response to pressure from the outside world. Common stress reactions include tension, irritability, inability to concentrate and a variety of physical symptoms that include headache and a fast heartbeat.
It's almost impossible to live without some stress. And most of us wouldn't want to, because it gives life some spice and excitement. But if stress gets out of control, it may harm the health, relationships and the enjoyment of life. $^{1}$

\section{Treatment of stress}

There are several ways of coping with stress. Some techniques of time management may help a person to control stress. Techniques of stress management may include some of the following as autogenic therapy, 
cognitive therapy, exercise, meditation, deep breathing, nootropic natural medicine, classical music and pharmacotherapy.

Millions of people around the world use traditional medicines to relieve the symptoms of the stress or to cure it. The main factors that make natural products attract candidates for human use include their ease of availability, cost effectiveness and presumed safety. The present study was therefore undertaken to investigate the efficacy of Ocimum sanctum on stress induced animals. ${ }^{2}$

\section{Objective}

The objective of the present study was to investigate the efficacy of Ocimum sanctum on stress induced animals.

\section{METHODS}

\section{Animals}

Wistar strain male albino rats weighing 180-220 g were bred in central animal house of Narayana Medical College, Nellore. Animals were housed in groups of three (rats) per cage and maintained in a temperature controlled room with a 12-hour light or dark cycle (lights on at 7:00 a.m.) and allowed free access to food and water. The experiments were approved by Institutional animal ethical committee with protocol number- 21/2009/NMC, dated 5-6-2009.

Male albino mice of 25-30 g bred in Central Animal House of Narayana Medical College, Nellore were used. The animals were kept under standard laboratory conditions, maintained on $12 \mathrm{~h}$ light or dark cycle, had free access to food and water. Animals were acclimatized to laboratory conditions before the test. Each animal was used once in the experiments. All the experiments were performed between 09:00 a.m. and 5:00 p.m.

\section{Experimental groups}

The animals were divided into different groups with six animals in each group.

\section{Ocimum sanctum extracts, preparation and dosage}

Fresh leaves of Ocimum sanctum were collected, identified and authenticated by botanist Mr. K. Vishnuvardhan, junior lecturer in Botany, Government Junior College, Venkatagiri, Nellore district. With plant identification number 10/2009/GJCV dated 08 March 2009. The leaves were thoroughly washed with tap water, dried in shade and grounded to make powder.

100 gms of powder of dried Ocimum sanctum was boiled with $100 \mathrm{ml}$ in distilled water in flask for 24 hours. The flask was kept on heating mantle for boiling till the content was reduced to half, then cooled, filtered using muslin cloth so as to remove the insoluble materials. The filtrate was poured in an ordinary, cleaned and already weighed petri dish was placed on hot plate for complete evaporation. Care was taken to avoid charring. Then the extract was cooled at room temperature, weighed to calculate extractability percentage and finally stored in desiccators in a cool and dry place.

\section{Alprazolam preparation and dosage}

Alprazolam tablets were purchased from Narayana Medical College of Pharmacy, Nellore (Anxinil, Ranbaxy, India). Being insoluble in nature alprazolam tablets were dissolved in $15 \%$ ethyl alcohol. The dose was adjusted to $0.25 \mathrm{mg} / \mathrm{kg}$ body weight. Tablet was mixed with $10 \mathrm{ml}$ of $15 \%$ ethyl alcohol and this mixture was given through oral route by using feeding cannula.

Animals: Mice (25-30 g).

Drugs used: Ocimum sanctum extract $(100 \mathrm{mg} / \mathrm{kg}$ body weight), alprazolam $(0.125-0.250 \mathrm{mg} / \mathrm{kg})$.

\section{Forced swim test- requirements}

Equipment: Rectangular glass jars $(25-12-25 \mathrm{~cm})$ containing fresh water, stop watch.

\section{Procedure}

Animals were weighed and numbered. The animals were randomized into two groups according to the body weights. Each group contains six animals. Individual animal was allowed to swim inside the jar $(25-12-25 \mathrm{~cm})$ containing fresh water up to $15 \mathrm{~cm}$ height. Mice were allowed swim for $6 \mathrm{~min}$. After initial struggle to escape for 1-2 min, the animal become immobile or has little movements to keep floating in the water. Total immobility period was measured during six minute test. ${ }^{3}$

\section{Rotarod test}

\section{Procedure}

On the day of testing, animals were kept in their home cages and acclimatized to the testing room at least for one hour. For ease of identification at later trails, the rats were marked by using non-toxic ink, with respective stripes at the base of the tail before testing.

Rotarod apparatus was turned on. It consists of three trails separated by $15 \mathrm{~min}$ inter trail intervals. It is possible to run the next batch of rats consecutively in one trail before moving to the next. There is no training period prior to the test phase.

Apparatus was set to accelerating mode from 4-40 rpm in 300 seconds, the apparatus will indicate acceleration waiting of $4 \mathrm{rpm}$ constant speed until the start button is pressed. 


\section{Test trail 1}

Rats were placed on the lanes. Latency period was recorded at which each rat falls off the rod. If a rat is clinging on the rod completes a full passive rotation, timer will be stopped for that rat by pushing the lever and record the latency. Such rats were removed and placed it back in its home cage. Other mice that are still running in the adjacent lanes were not disturbed. Apparatus was cleaned with water then with ethyl alcohol, wiped it dry. Next set of mice were tested repeating the procedure. ${ }^{4} 15$ min inter trail interval was given between consecutive trails of the same batch of mice. At the end of trail 3, each mice was weighed and body weights were noted on the data sheet.

\section{Statistical method}

Student t-test was used to analyse the data.

\section{RESULTS}

Anti-stress activity of Ocimum sanctum in mice was demonstrated by measuring the immobility period during forced swim test. Ocimum sanctum had reduced the stress in mice (mean- 31.50) compared to standard drug (mean32.33). But the difference in values was statistically insignificant (Table 1).

Table 1: Change from baseline.

\begin{tabular}{|lll|}
\hline Forced swim test & \multicolumn{2}{l|}{ Change from baseline } \\
\hline n=6 & Alprazolam & Ocimum sanctum \\
\hline Mean & 32.33 & 31.50 \\
\hline S.D & 16.23 & 7.662 \\
\hline P value & 0.9121 & \\
\hline
\end{tabular}

The measurement of the latency period of rats was performed by rotarod apparatus. Ocimum sanctum (latency period- $14.67 \mathrm{sec}$ ) had shown less magnitude of anti-stress activity when compared to alprazolam (17.17 $\mathrm{sec})$. When the values were taken from change in the baseline the $p$ value was 0.535 and this value is statistically insignificant value (Table 2).

Table 2: Change from baseline.

\begin{tabular}{|lll|}
\hline Rotarod test & \multicolumn{2}{l|}{ Change from baseline } \\
\hline n=6 & Alprazolam & Ocimum sanctum \\
\hline Mean & 17.17 & 14.67 \\
\hline S.D & 8.010 & 5.164 \\
\hline P value & 0.535 & \\
\hline
\end{tabular}

\section{DISCUSSION}

The present study was aimed at investigating the antistress effects of Ocimum sanctum and comparing it with alprazolam in mice. Ocimum sanctum is a medicinal plant distributed mainly in the tropical and subtropical regions. Besides being widely used as a religion plant, it has also been used as indigenous medicine in several countries in Asia and Africa. ${ }^{5}$

Alprazolam is a drug belonging to newer benzodiazepine group. It is an antianxiety drug. Benzodiazepines (BZD) preferentially act on the mid brain, ascending reticular formation, limbic system by enhancing the presynaptic or post synaptic inhibition through a specific BZD receptor which is an integral part of the GABA-A receptor chloride channel complex. Forced swim test is used to evaluate the effects of the drugs like antidepressants in the central nervous system. In the present study, normal control mice were allowed to swim for six minutes in order to induce stress.

When Ocimum sanctum and alprazolam were administered to stress induced mice, these drugs significantly decreased the immobility period. ${ }^{6,7}$ Administration of Ocimum sanctum and alprazolam has altered the behavioral performance of stress induced mice in forced swim test. The change period induced by stress was significantly ameliorated by a single oral administration of alprazolam and Ocimum sanctum as these drugs significantly decreased the immobility period because of their anti-stress effect.

The change induced after administration of Ocimum sanctum is in according to the mobility period after administration study conducted by Bhargva et al who have reported Ocimum sanctum to possess adaptogenic [anti-stress] properties. ${ }^{8}$ The drug increased the physical endurance, survival time of swimming mice, prevented stress induced ulcers in mice. However, Ocimum sanctum has less magnitude of anti-stress activity when compared to alprazolam in forced swim test.

Even the study conducted by Grover et al have reported that Tulsi powder $(20,40 \mathrm{mg} / \mathrm{kg})$ and its extracts (aqueous and alcoholic 10, $20 \mathrm{mg} / \mathrm{kg}$ ) when given for 7 days prior to heat stress prevented the reduction in ascorbic acid content of adrenals and heart. ${ }^{9}$

The stress induced impairment of rotarod performance was significantly ameliorated by both alprazolam and Ocimum sanctum after administration of single dose. However, Ocimum sanctum has less magnitude of antistress activity when compared to alprazolam. Ameliorating effect of alprazolam and Ocimum sanctum on stress induced impairment of rotarod performance is thought to be based on the anti-stress effect. This effect could bedue to sedative action as well as ataxic action of alprazolam and Ocimum sanctum and might be acting through the serotonergic system or it could be due to the change in the humoral response as reported by Mediratta et al have reported that Ocimum sanctum modulates the humoral response by acting at various levels in the immune mechanism such as antibody production, release 
of mediators of hypersensitivity reactions and tissue response to thesemediators. . $^{10,11}$

Although mechanism of action of anti-stress activity of alprazolam is well known but the exact mechanism of action of Ocimum sanctum is yet to be ascertained. Ocimum sanctum plant contains alkaloids, glycosides, tannins and saponins. The leaves contain ascorbic acid $(85 \mathrm{mg} / 100 \mathrm{mg})$ and carotene $(2.5 \mathrm{mg} / 100 \mathrm{mg})$.

The overall activity of Ocimum may be due to the numerous constituents which have been described by Satyavati et al that is gas liquid chromatography of the essential oil also revealed the presence of eugenol (70\%) as major constituent. ${ }^{12}$

Other components identified were nerol, eugenol methyl ether, caryophyllene, terpinene 4-01, decyaldehyde, gamma selinene, alfa-pinene, beta-pinene, camphor and carvacrol 41, Ramachandra et al have reported that the leaves yield ursolic acid, apigenin, luteolin, apigenin-7-0glucuronide, luteolin 7-0 glucoronide and molludistin 58 . The mechanism of action of Ocimum sanctum may due to exhibition of cortisol sparing effect. They act on the central nervous system as a stimulant. They may act as immune stimulant. ${ }^{13}$

It scavenges free radicals in the brain, induces a state of non-specific increased resistance. However, the exact mechanism of action needs to be evaluated and hence further studies are needed.

\section{CONCLUSION}

The present study of "Demonstration of anti-stress activity of Ocimum sanctum and alprazolam" on two experimental animal models was conducted in the department of pharmacology. The present study was taken up and anti-stress activity of Ocimum sanctum was compared with a standard drug that is alprazolam. Both forced swim test and rotarod test experimental procedures were compared with standard anti stress drug alprazolam. The result of the present study suggests that Ocimum sanctum possess significant anti-stress activity. However, the magnitude of anti-stress activity of Ocimum sanctum was less when compared to alprazolam.

Funding: No funding sources Conflict of interest: None declared

Ethical approval: The study was approved by the Institutional Ethics Committee

\section{REFERENCES}

1. Quick JC, Wright TA, Adkins JA, Nelson DL, Quick JD. MD, MPH, FACPM. Preventive stress management in organizations. 2nd ed. Washington,
DC: United States: American Psychological Association; 1997.

2. Bhattacharya SK, Bhattacharya A, Das K, Muruganandam AV, Sairam K. Further investigations on the antioxidant activity of Ocimum sanctum using different paradigms of oxidative stress in rats. $\mathbf{J}$ Natural Remed. 2001;1:6-16.

3. Butterweck V, Wall A, Lieflaender-Wulf U, Winterhoff $H$, Nahrstedt A. Effects of the total extract and fractions of Hypericum perforatum in animal assays for antidepressant activity. Pharmacopsychiatr. 1997;30:117-24.

4. Khanna N, Bhatia J. Antinociceptive action of Ocimum sanctum (Tulsi) in mice: possible mechanisms involved. J Ethnopharmacol. 2003;88(23):293-6.

5. Singh S, Nair V, Jain S, Gupta YK. Evaluation of anti-inflammatory activity of plant lipids containing $\alpha$-linolenicacid. Indian J Exp Biol. 2008;46(6):453-6.

6. Singh N, Misra N, Srivastava AK, Dixit KS, Gupta GP. Effect of anti-stress plants on biochemical changes during stress reaction. Indian J Pharmacol. 1991;23:137-42.

7. Bhattacharyya D, Sur TK, Jana U, Debnath PK. Controlled programmed trial of Ocimum sanctum leaf ongeneralized anxiety disorders. Nepal Med Coll J. 2008;10(3):176-9.

8. Bhargava KP, Singh N. Anti-stress activity of Ocimum sanctum Linn. Indian $J$ Med Res. 1981;73:443-51.

9. Grover JK, Gupta M, Midha V. Effect of adaptogen Ocimum sanctum on the ascorbic acid and cholesterol contents of heart and adrenals after heat stress in albino rats. Indian $\mathrm{J}$ Pharmacol. 1987;19:149.

10. Imbe H, Iwai-Liao Y, Senba E. Stress induced hyperalgesia: animal model and putative mechanisms. Front Biosci. 2006;11:2179-92.

11. Liu J, Wang X, Mori A. Immobilisation stressinduced antioxidant defense changes in rat plasma, effect of treatment with reduced glutathione. Int J Biochem. 1994;26:511-7.

12. Satyavati GV, Gupta AK, Neeraj T. Ocimum sanctum linn. Medicinal Plants of India. 2nd ed. New Delhi, India: ICMR Publication; 1987: 354-371.

13. Ramachandran NAG, Gunasegaran R. Chemical investigations of certain Indian plants. Indian $\mathbf{J}$ Chemistr. 1982;21:979-80.

Cite this article as: Hemanth GV, Kudagi BL, Buchineni M, Pathapati RM, Rayam S. Anti-stress activity of Ocimum sanctum and alprazolam in animal models. Int J Basic Clin Pharmacol 2019;8:2224-7. 